that approximately half of the $14300 \mathrm{pa}$ tients detained had not been resident for 6 months (Mental Health Act Commission, 2006b). A majority of all detained patients are likely to spend at least an initial period in acute or admission units, and many will not move into 'long-term residential units'. The Mental Health Act Commission has suggested that the Government should consider widening the scope of the proposed regulations to allow units where patients are detained to qualify as 'specified premises' and to provide indoor designated smoking facilities.

Jochelson, K. (2006) Smoke-free legislation and menta health units: the challenges ahead. British Journal of Psychiatry, 189, 479-480.

Mental Health Act Commission (2006a) Eleventh Biennial Report 2003-2005. TSO (The Stationery Office)

Mental Health Act Commission (2006b) Response to the Department of Health Smoke-Free Regulations Consultation. MHAC Policy Briefing (issue 14, August 2006) Annex C. http: //www.mhac.org.uk/Pages/ policybriefings.html

A.Williams Rhiwbina, Cardiff, UK Email: ajimwilliams@btinternet.com doi: 10.1192/bjp.190.5.449a

\section{X-chromosome abnormality and schizophrenia}

Van Rijn et al (2006) concluded that their findings suggested a link between an $\mathrm{X}$ chromosomal abnormality and liability to schizophrenia which might be useful in the search for the genetic aetiology. Moreover they stated that a crucial role for $\mathrm{X}$ chromosome abnormalities in this context has been proposed by Lishman (1998). In 1966 Hambert described a group of 75 XXY men, of whom 17 had hallucinations, 21 paranoid ideas, 9 'megalomanic ideas' and 5 'short periods of mania-like disorder'. Penrose (1966) claimed that 'the effects of sex chromosomal disorders are more noticeable in relation to alterations in character and stability than to intellectual loss. Olanders (1975), working in the same research group as Hambert and Penrose, reported 16 women with schizophrenia among 31 with triple $\mathrm{X}$ syndrome. Olanders' own psychiatric investigation of these women revealed many with paranoid symptoms who did not meet his strict criteria for schizophrenia. He described a paranoid syndrome in 8 , hallucinations in 4 , confusion in 3 and catatonic symptoms in 2 .
Van Rijn et al discuss the relationship between an extra $\mathrm{X}$ chromosome and psychosis through the 'decreased cerebral lateralisation' hypothesis. Netley \& Rovet (1982) reviewed data which point to diminished cerebral cell numbers owing to lower mitotic rates which also result in the lower dermal ridge counts. I think that a lower cerebral cell number could give rise to decreased cerebral lateralisation, but this needs further investigation.

In my opinion, Van Rijn et al present no new data but have rediscovered what was known for a long time.

Hambert, G. (1966) Males with Positive Sex Chromatin. An Epidemiologic Investigation Followed by Psychiatric Study of Seventy-Five Cases. Akademiförlaget.

Lishman, W. A. (1998) Endocrine diseases and metabolic disorders. In Organic Psychiatry: The Psychological Consequences of Cerebral Disorder (ed.W. A. Lishman), pp. 526-527. Blackwell Science.

Netley, C. \& Rovet, J. (1982) Verbal deficits in children with 47,XXYand 47,XXX karyotypes: a descriptive and experimental study. Brain and Language, I7, 58-72.

Olanders, S. (1975) Other psychiatric findings. In Females with Supernumerary X Chromosomes. A Study of 39 Psychiatric Cases, pp. $91-104$. Scandinavian University Books.

Penrose, L. S. (1966) The contribution of mental deficiency research to psychiatry. British Journal of Psychiatry, II2, 747-755.

Van Rijn, S., Aleman, A., Swaab, H., et al (2006) Klinefelter's syndrome (karyotype 47,XXY) and schizophrenia-spectrum pathology. British journal of Psychiatry, 189, 459-460.

M. Otter Bennekom, The Netherlands. Email maarten.otter@fitternet.nl

doi: 10.II92/bjp.190.5.450

Authors' reply: Otter claims that our finding of high levels of schizophrenia symptoms in XXY men is a rediscovery of what has been known for a long time. $\mathrm{He}$ supports his claim by referring to reports on triple $\mathrm{X}$ syndrome that were not published in peer-reviewed journals from the University of Gothenburg. We acknowledge that previous studies have also reported psychopathology in XXY men. However, we also point out that these studies have been limited in that they described men with Klinefelter's syndrome in psychiatric care or recorded hospital admissions. Our findings in a non-selected sample of XXY men, using valid and reliable dimensional measures of psychopathology, corroborate and extend the data derived from these earlier studies.
With regard to the novelty of the findings, it is interesting to note that none of the major reviews on Klinefelter's syndrome (Smyth \& Bremner, 1998; Lanfranco et al, 2004) report a vulnerability for schizophrenia psychopathology, indicating that this is not a generally accepted feature. In addition, the aim of our study was not to provide a comprehensive review of psychopathology in X chromosomal disorders, but we find the presence of schizophrenia psychopathology in XXX females very interesting as it supports our suggestion of a link between the $\mathrm{X}$ chromosome and schizophrenia symptoms.

Finally, Otter argues that reduced cerebral lateralisation in Klinefelter's syndrome has been suggested by neurobiological studies but is yet to be proved. However, a recent functional neuroimaging study has also presented evidence for reduced lateralisation in brain perfusion in XXY men (Itti et al, 2003).

In conclusion, we feel that the evidence put forward by Otter merely underscores the importance of our findings, as both triple $\mathrm{X}$ and Klinefelter's syndrome have been associated with schizophrenia symptoms. Including both syndromes in genetic studies would advance the understanding of a link between the $\mathrm{X}$ chromosome and schizophrenia pathology.

Itti, E., Gaw Gonzalo, I. T., Boone, K. B., et al (2003) Functional neuroimaging provides evidence of anomalous cerebral laterality in adults with Klinefelter's syndrome. Annals of Neurology, 54, 669-673.

Lanfranco, F., Kamischke, A., Zitzmann, M., et al (2004) Klinefelter's syndrome. Lancet, 364, 273-283.

Smyth, C. M. \& Bremner, W. J. (1998) Klinefelter syndrome. Archives of Internal Medicine, 158, 1309-13|4.

S.Van Rijn Department of Psychiatry, Rudolf Magnus Institute for Neuroscience, University Medical Centre, Utrecht, and Psychological Laboratory, Helmholtz Institute, Utrecht University, The Netherlands. Email: S.vanRijn@fss.uu.nl

A. Aleman Psychological Laboratory, Helmholtz Institute, Utrecht University and BCN Neurolmaging Centre, University of Groningen, The Netherlands

H. Swaab Department of Psychiatry, Rudolf Magnus Institute for Neuroscience, University Medical Centre, Utrecht and Department of Clinical Child and Adolescent Studies, Leiden University, The Netherlands

R. S. Kohn Department of Psychiatry, Rudolf Magnus Institute for Neuroscience, University Medical Centre Utrecht, The Netherlands doi: 10.I192/bjp.190.5.450a 